Bull. Chem. Soc. Ethiop. 2014, 28(1), 73-79.

Printed in Ethiopia

DOI: http://dx.doi.org/10.4314/bcse.v28i1.9

ISSN 1011-3924

(C) 2014 Chemical Society of Ethiopia

\title{
SYNTHESIS, IR AND NMR SPECTRAL CORRELATIONS IN SOME SYMMETRICAL DIIMINES
}

\author{
G. Thirunarayanan ${ }^{*}$ \\ Department of Chemistry, Annamalai University, Annamalainagar-608002, India
}

(Received February 27, 2013; revised July 21, 2013)

\begin{abstract}
A series of diimines have been synthesized by coupling of diamine with substituted benzaldehydes. The purities of these diimines were checked by their analytical and spectroscopic data. The spectral frequencies $\mathrm{vCN}\left(\mathrm{cm}^{-1}\right)$, NMR chemical shifts $(\delta, \mathrm{ppm})$ of $\mathrm{C}-\mathrm{H}$ and $\mathrm{C}=\mathrm{N}$ of these diimines have been correlated with Hammett substituent constants, F and $\mathrm{R}$ parameters using single and multi-linear regression analysis. From the results of statistical analysis, the effect of substituents on the above spectral data has been studied.
\end{abstract}

KEY WORDS: Diimines, IR and NMR spectra, Spectral correlation, Hammett sigma constants

\section{INTRODUCTION}

In this decade synthesis of enantiometrically pure compounds from prochiral compounds using chiral reagents have become topic of immense interest. Effective and enthusiastic efforts by synthetic organic chemists in the last two decades are converting this difficult task to a practically possible level. Many chiral molecules have been synthesized in excellent optical purities through chemical process which reveal natural processes. Aldehydes and ketones react with primary amines to give imines, in which the carbon-oxygen double bond is replaced by a carbon-nitrogen double bond was discovered in 1864 by Hugo Schiff [1] and been always the reaction of interest to chemists up to date in the fields of macrocyclic and supramolecular chemistry. The diimines or bisimines or bis-Schiff's bases also been synthesised by the reaction of 1 mole diamine with 2 moles of aldehydes or ketones. Primary amine and $\beta$-diketones also used for synthesis of cyclic diimines. Optically active amines and alkaloids, with a wide range of molecular structures are used as chiral reagents. Numerous solvent assisted [2] or solvent free greener [3] methods and reagents were available in the literature for synthesis of optically active diimines. These diimines have been used as a precursor for synthesis of optically active cyclic imines like piperazine derivatives [4], heterocycles such as imidazolines, pyrimidines, carbapenem intermediates, bis- $\beta$-lactams, bisketenes [5, 6], polymers[7] and many metal complexes[8]. Diimines possess important biological activities such as antioxidant [9], antiinflammatory and anti-analgesics [10]. Spectroscopic data were used for prediction of ground state molecular equilibration of organic compounds such as, ketones, chalcones [11], imines [12], diimines [13], acyl chlorides [14], bromides and their esters [15]. Recently, Suresh et al., [12] have studied the effects of substituent on infrared $\mathrm{C}=\mathrm{N}$, nuclear magnetic resonance chemical shifts (ppm) $\delta \mathrm{CH}$ and $\mathrm{CN}$. In this work they observed good, satisfactory and fair degree of correlations for the above frequencies with Hammett substituent constants, $\mathrm{F}$ and $\mathrm{R}$ parameters. In this view, there is no report available for the synthesis and spectral correlations of diimines in literature in the past. Therefore the author has taken efforts to synthesis and studied the effect of substituents on the spectral group frequencies of synthesized diimines.

*Corresponding author. E-mail: drgtnarayanan@gmail.com 


\section{EXPERIMENTAL}

\section{General}

All the chemicals involved in the present investigation were procured from Sigma-Aldrich and E-Merck chemical companies. Melting points of all diimines were determined in open glass capillaries on SUNTEX melting point apparatus and are uncorrected. Infrared spectra $(\mathrm{KBr}$, 4000-400 $\mathrm{cm}^{-1}$ ) were recorded on AVATAR-300 Fourier transform spectrophotometer. The Bruker AV400 NMR spectrometer was used for recording NMR spectra operating $400 \mathrm{MHz}$ for ${ }^{1} \mathrm{H}$ and $100 \mathrm{MHz}$ for ${ }^{13} \mathrm{C}$ spectra in $\mathrm{CDCl}_{3}$ solvent using TMS as internal standard. Mass spectra of diimines were recorded on SHIMADZU spectrometer using chemical ionization technique.

\section{Synthesis of diimines}

To a solution of aryl aldehydes $(100 \mathrm{mmol})$ in methanol $(80 \mathrm{~mL})$ was added ethylenediamine $(60 \mathrm{mmol})$ at $0{ }^{\circ} \mathrm{C}$ slowly in drops. Then the reaction mixture was stirred at room temperature for $12 \mathrm{~h}$ (Scheme 1) [4]. The crude diimines were subjected to evacuate under vacuum. The residue was treated with $100 \mathrm{~mL}$ of methylene chloride and dried over anhydrous potassium carbonate. The diimines were obtained after evaporated the solvent under high vacuum. The analytical, physical constants and mass fragments of these diimines are presented in Table 1. The infrared and NMR spectroscopic data of these diimines are given in Table 2.

\begin{tabular}{|c|c|c|}
\hline$+2 \mathrm{OH}$ & $0^{\circ} \mathrm{C}, 12 \mathrm{l}$ & (1-11 \\
\hline Entry & $\mathrm{R}$ & $x$ \\
\hline 1 & $\mathrm{Ph}$ & $\mathrm{H}$ \\
\hline 2 & $\mathrm{Ph}$ & $2-\mathrm{Cl}$ \\
\hline 3 & $\mathrm{Ph}$ & $4-\mathrm{Cl}$ \\
\hline 4 & $\mathrm{Ph}$ & $4-\mathrm{N}\left(\mathrm{CH}_{3}\right)_{2}$ \\
\hline 5 & $\mathrm{Ph}$ & $4-\mathrm{N}\left(\mathrm{C}_{2} \mathrm{H}_{5}\right)_{2}$ \\
\hline 6 & $\mathrm{Ph}$ & $4-\mathrm{OH}$ \\
\hline 7 & $\mathrm{Ph}$ & $2-\mathrm{OCH}_{3}$ \\
\hline 8 & $\mathrm{Ph}$ & $4-\mathrm{OCH}_{3}$ \\
\hline 9 & $\mathrm{Ph}$ & $4-\mathrm{CH}_{3}$ \\
\hline 10 & 2-Pyridine & $\mathrm{H}$ \\
\hline 11 & 2-Thienyl & $\mathrm{H}$ \\
\hline
\end{tabular}

Scheme 1. Synthesis of diimines. 
Table 1. The analytical, physical constants and mass fragments $(\mathrm{m} / \mathrm{z})$ of diimines.

\begin{tabular}{|l|l|l|c|c|l|l|}
\hline Entry & $\mathrm{X}$ & M.F. & M.W. & Yield (\%) & m.p. $\left({ }^{\circ} \mathrm{C}\right)$ & Mass (m/z) \\
\hline 1 & $\mathrm{H}$ & $\mathrm{C}_{16} \mathrm{H}_{16} \mathrm{~N}_{2}$ & 236 & 94 & $\begin{array}{l}39-49 \\
38-40[4]\end{array}$ & $236\left[\mathrm{M}^{+}\right]$ \\
\hline 2 & $2 \mathrm{Cl}$ & $\mathrm{C}_{16} \mathrm{H}_{14} \mathrm{Cl}_{2} \mathrm{~N}_{2}$ & 304 & 89 & $\begin{array}{l}87-88 \\
84-88[15]\end{array}$ & $\begin{array}{l}304\left[\mathrm{M}^{+}\right], 306\left[\mathrm{M}^{+2}\right], \\
308\left[\mathrm{M}^{+4}\right]\end{array}$ \\
\hline 3 & $4-\mathrm{Cl}$ & $\mathrm{C}_{16} \mathrm{H}_{14} \mathrm{Cl}_{2} \mathrm{~N}_{2}$ & 304 & 89 & $\begin{array}{l}140-141 \\
140-142[4]\end{array}$ & $\begin{array}{l}304\left[\mathrm{M}^{+}\right], 306\left[\mathrm{M}^{+2}\right], \\
308\left[\mathrm{M}^{+4}\right]\end{array}$ \\
\hline 4 & $4-\mathrm{N}\left(\mathrm{CH}_{3}\right)_{2}$ & $\mathrm{C}_{20} \mathrm{H}_{26} \mathrm{~N}_{4}$ & 322 & 85 & $\begin{array}{l}174-175 \\
173-174[10]\end{array}$ & $322\left[\mathrm{M}^{+}\right]$ \\
\hline 5 & $4-\mathrm{N}\left(\mathrm{C}_{2} \mathrm{H}_{5}\right)_{2}$ & $\mathrm{C}_{24} \mathrm{H}_{34} \mathrm{~N}_{4}$ & 378 & 86 & $\begin{array}{l}115-116 \\
114-116[10]\end{array}$ & $378\left[\mathrm{M}^{+}\right]$ \\
\hline 6 & $2-\mathrm{OH}$ & $\mathrm{C}_{16} \mathrm{H}_{16} \mathrm{~N}_{2} \mathrm{O}_{2}$ & 268 & 87 & $\begin{array}{l}121-122 \\
120-122[10]\end{array}$ & $268\left[\mathrm{M}^{+}\right]$ \\
\hline 7 & $2-\mathrm{OCH} 3$ & $\mathrm{C}_{18} \mathrm{H}_{20} \mathrm{~N}_{2} \mathrm{O}_{2}$ & 296 & 93 & $\begin{array}{l}113-114 \\
112-114[4]\end{array}$ & $296\left[\mathrm{M}^{+}\right]$ \\
\hline 8 & $4-\mathrm{OCH} 3$ & $\mathrm{C}_{18} \mathrm{H}_{20} \mathrm{~N}_{2} \mathrm{O}_{2}$ & 296 & 94 & $\begin{array}{l}108-109 \\
106-108[4]\end{array}$ & $296\left[\mathrm{M}^{+}\right]$ \\
\hline 9 & $4-\mathrm{CH}_{3}$ & $\mathrm{C}_{18} \mathrm{H}_{20} \mathrm{~N}_{2}$ & 264 & 90 & $\begin{array}{l}152-154 \\
152-154[4]\end{array}$ & $264\left[\mathrm{M}^{+}\right]$ \\
\hline 10 & $2-\mathrm{Pyridine}$ & $\mathrm{C}_{14} \mathrm{H}_{14} \mathrm{~N}_{4}$ & 238 & 85 & $\begin{array}{l}138-140 \\
139[16]\end{array}$ & $238\left[\mathrm{M}^{+}\right]$ \\
\hline 11 & $2-\mathrm{Thienyl}$ & $\mathrm{C}_{12} \mathrm{H}_{12} \mathrm{~N}_{2} \mathrm{~S}_{2}$ & 248 & 86 & $\begin{array}{l}83-84 \\
82-84[10]\end{array}$ & $248\left[\mathrm{M}^{+}\right]$ \\
\hline
\end{tabular}

Table 2. The infrared $\nu \mathrm{CN}\left(\mathrm{cm}^{-1}\right)$ frequencies, $\mathrm{NMR} \delta(\mathrm{ppm})$ of $\mathrm{C}-\mathrm{H}$ and $\mathrm{C}=\mathrm{N}$ of diimines.

\begin{tabular}{|l|l|l|l|l|}
\hline Entry & Substituent & $\begin{array}{l}\text { IR } \\
\mathrm{C}=\mathrm{N}\end{array}$ & $\begin{array}{l}{ }^{1} \mathrm{H} \text { NMR } \\
\mathrm{CH}=\mathrm{N}\end{array}$ & $\begin{array}{l}{ }^{3} \mathrm{C} \text { NMR } \\
\mathrm{C}=\mathrm{N}\end{array}$ \\
\hline $\mathbf{1}$ & $\mathrm{H}$ & 1649 & 8.294 & 162.72 \\
\hline $\mathbf{2}$ & $2-\mathrm{Cl}$ & 1638 & 8.725 & 159.75 \\
\hline $\mathbf{3}$ & $4-\mathrm{Cl}$ & 8.231 & 161.32 \\
\hline $\mathbf{4}$ & $4-\mathrm{N}\left(\mathrm{CH}_{3}\right)_{2}$ & 1645 & 8.152 & 159.72 \\
\hline $\mathbf{5}$ & $4-\mathrm{N}\left(\mathrm{C}_{2} \mathrm{H}_{5}\right)_{2}$ & 1642 & 7.562 & 160.86 \\
\hline $\mathbf{6}$ & $2-\mathrm{OH}$ & 1638 & 8.351 & 164.17 \\
\hline $\mathbf{7}$ & $2-\mathrm{OCH}_{3}$ & 1633 & 8.713 & 158.73 \\
\hline $\mathbf{8}$ & $4-\mathrm{OCH}_{3}$ & 1643 & 8.216 & 161.82 \\
\hline $\mathbf{9}$ & $4-\mathrm{CH}_{3}$ & 1633 & 8.245 & 162.54 \\
\hline $\mathbf{1 0}$ & 2-Pyridine & 1645 & 8.305 & 156.58 \\
\hline $\mathbf{1 1}$ & 2-Thienyl & 1632 & 8.441 & 159.57 \\
\hline
\end{tabular}

RESULTS AND DISCUSSION

\section{Infrared spectral study}

In the present study, author has recorded the infrared spectrum of all synthesised diimines containing single substituents in phenyl moieties with $\mathrm{KBr}$ disc. The $\mathrm{C}=\mathrm{N}$ stretches $\left(\mathrm{cm}^{-1}\right)$ of all diimines have been assigned and listed in Table 2. These stretches $\left(\mathrm{cm}^{-1}\right)$ were correlated with Hammett substituent constants, $\mathrm{F}$ and $\mathrm{R}$ parameters. In this correlation, the Hammett equation is employed as,

$v=\rho \sigma+v_{0}$

Bull. Chem. Soc. Ethiop. 2014, 28(1) 
where $v_{0}$ is the frequency for the parent member of the series. The assigned $v \mathrm{C}=\mathrm{N}$ stretching frequencies $\left(\mathrm{cm}^{-1}\right)$ were correlated with various Hammett substituent constants and $\mathrm{F}$ and $\mathrm{R}$ parameters through single and multi-regression analyses [12, 17-19] including Swain-Lupton's parameters [20]. The results of statistical analysis of single parameter correlation are shown in Table 3.

Table 3. Results of statistical analysis of IR $\vee \mathrm{C}=\mathrm{N}\left(\mathrm{cm}^{-1}\right), \mathrm{NMR} \delta^{1} \mathrm{H}(\mathrm{ppm}) \mathrm{CH}=\mathrm{N}$ and $\delta^{13} \mathrm{C}(\mathrm{ppm}) \mathrm{C}=\mathrm{N}$ of $\mathrm{N}, \mathrm{N}^{\prime}$-arylidineethane-1,2-diamines with Hammett substituent constants $\sigma, \sigma^{+}, \sigma_{\mathrm{I}}, \sigma_{\mathrm{R}}, \mathrm{F}$ and $\mathrm{R}$ parameters.

\begin{tabular}{|c|c|c|c|c|c|c|c|}
\hline Frequency & Constants & $\mathrm{r}$ & I & $\rho$ & $s$ & $\mathrm{n}$ & Correlated derivatives \\
\hline \multirow[t]{6}{*}{$v \mathrm{C}=\mathrm{N}\left(\mathrm{cm}^{-1}\right)$} & $\sigma$ & 0.931 & 1640.91 & 7.029 & 5.61 & 8 & $\begin{array}{l}\mathrm{H}, 2-\mathrm{Cl}, 4-\mathrm{Cl}, 4-\mathrm{Me}, 4-\mathrm{N}\left(\mathrm{CH}_{3}\right)_{2}, 4-\mathrm{OH}, 4- \\
\mathrm{OCH}_{3}, 4-\mathrm{OCH}_{3}\end{array}$ \\
\hline & $\sigma^{+}$ & 0.717 & 1640.33 & 1.506 & 5.98 & 8 & \\
\hline & $\sigma_{I}$ & 0.803 & 1639.57 & 0.922 & 6.07 & 8 & \\
\hline & $\sigma_{R}$ & 0.904 & 1643.50 & 11.050 & 5.37 & 8 & \\
\hline & $\mathrm{F}$ & 0.804 & 1640.11 & 1.587 & 6.06 & 8 & \\
\hline & $\mathrm{R}$ & 0.833 & 1642.30 & 6.021 & 5.68 & 8 & \\
\hline \multirow[t]{6}{*}{$\delta \mathrm{CH}=\mathrm{N}(\mathrm{ppm})$} & $\sigma$ & 0.902 & 8.396 & 0.184 & 0.23 & 8 & $\begin{array}{l}\mathrm{H}, 2-\mathrm{Cl}, 4-\mathrm{Cl}, 4-\mathrm{Me}, 4-\mathrm{N}\left(\mathrm{CH}_{3}\right)_{2}, 4-\mathrm{OH}, 4- \\
\mathrm{OCH}_{3}, 4-\mathrm{OCH}_{3}\end{array}$ \\
\hline & $\sigma^{+}$ & 0.907 & 8.431 & 0.196 & 0.21 & 8 & \\
\hline & $\sigma_{I}$ & 0.875 & 8.231 & 0.586 & 0.28 & 8 & \\
\hline & $\sigma_{R}$ & 0.857 & 8.307 & 0.170 & 0.23 & 8 & \\
\hline & $\mathrm{F}$ & 0.841 & 8.227 & 0.579 & 0.22 & 8 & \\
\hline & $\mathrm{R}$ & 0.811 & 8.704 & 0.908 & 0.24 & 8 & \\
\hline \multirow[t]{6}{*}{$\delta \mathrm{C}=\mathrm{N}(\mathrm{ppm})$} & $\sigma$ & 0.900 & 161.56 & 1.321 & 1.93 & 8 & $\begin{array}{l}\mathrm{H}, 2-\mathrm{Cl}, 4-\mathrm{Cl}, 4-\mathrm{Me}, 4-\mathrm{N}\left(\mathrm{CH}_{3}\right)_{2}, 4-\mathrm{OH}, 4- \\
\mathrm{OCH}_{3}, 4-\mathrm{OCH}_{3}\end{array}$ \\
\hline & $\sigma^{+}$ & 0.817 & 161.53 & 0.482 & 1.95 & 8 & \\
\hline & $\sigma_{I}$ & 0.835 & 162.06 & 3.425 & 1.85 & 8 & \\
\hline & $\sigma_{R}$ & 0.827 & 162.00 & 1.932 & 1.91 & 8 & \\
\hline & $\mathrm{F}$ & 0.828 & 162.07 & 3.067 & 1.90 & 8 & \\
\hline & $\mathrm{R}$ & 0.800 & 161.89 & 1.291 & 1.92 & 8 & \\
\hline
\end{tabular}

$\mathrm{r}=$ correlation co-efficient; $\rho=$ slope $; \mathrm{I}=$ intercept $\mathrm{s}=$ standard deviation; $\mathrm{n}=$ number of substituents.

The correlation of $\nu \mathrm{C}=\mathrm{N}\left(\mathrm{cm}^{-1}\right)$ frequencies of diimines with Hammett $\sigma$ constants and $\mathrm{R}$ parameters were found to be satisfactory. All correlations gave positive $\rho$ values. This implies that the normal substituent effect operates in all systems. The remaining constants gave poor correlations with $v \mathrm{C}=\mathrm{N}\left(\mathrm{cm}^{-1}\right)$ frequencies. This is due to the absence of polar, field and inductive effects of the substituents were unable to predict the reactivity on $\mathrm{C}=\mathrm{N}$ stretches. This is associated with the conjugative structure shown in (Figure 1).

Figure. 1. The resonance conjugative structure.

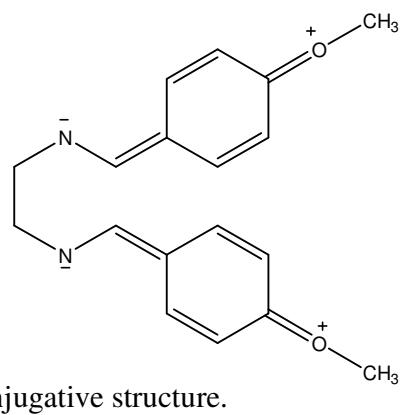

Bull. Chem. Soc. Ethiop. 2014, 28(1) 
In short, some of the single parameter correlations of $v \mathrm{C}=\mathrm{N}\left(\mathrm{cm}^{-1}\right)$ frequencies with Hammett substituent constants fail in correlation. So, the author think that it is worthwhile to seek the multi regression analysis which may produce a satisfactory correlation with Resonance, Field and Swain-Lupton's [20] constants. This is shown in the multi-correlation equations 2 and 3.

$$
\begin{aligned}
& v_{\mathrm{C}=\mathrm{N}}\left(\mathrm{cm}^{-1}\right)=1642.87( \pm 4.186)+3.944( \pm 1.144) \sigma_{\mathrm{I}}+11.750( \pm 9.491) \sigma_{\mathrm{R}} \\
& (r=0.948, \mathrm{n}=8, p>90 \%) \\
& v_{\mathrm{C}=\mathrm{N}}\left(\mathrm{cm}^{-1}\right)=1642.18( \pm 4.721)+0.602( \pm 0.142) \mathrm{F}+6.076( \pm 0.729) \mathrm{R} \\
& (r=0.935, \mathrm{n}=8, p>90 \%) \\
& { }^{1} H \text { NMR spectral study }
\end{aligned}
$$

The ${ }^{1} \mathrm{H}$ NMR spectra of the diimine derivatives under the present investigation were recorded in deuteriochloroform solution employing tetramethylsilane (TMS) as internal standard. The signals of the imine protons have been assigned and are presented in Table 2.

In nuclear magnetic resonance spectra, the ${ }^{1} \mathrm{H}$ or the ${ }^{13} \mathrm{C}$ chemical shifts $(\delta)(\mathrm{ppm})$ depend on the electronic environment of the nuclei concerned. These chemical shifts have been correlated with reactivity parameters. Thus the Hammett equation has been used in the form as shown in (4).

$\Delta=\delta_{0}+\rho \sigma$

where $\delta_{0}$ is the chemical shift of the corresponding parent compound.

The assigned proton chemical shifts (ppm) of diimines have been correlated [12, 17-19] with various Hammett sigma constants, $\mathrm{F}$ and $\mathrm{R}$ parameters. The results of statistical analysis are presented in Table 3. Hammett $\sigma$ and $\sigma^{+}$constants gave satisfactory correlation for these proton chemical shifts $(\mathrm{ppm})$. The remaining Hammett substituent constants, $\mathrm{F}$ and $\mathrm{R}$ parameters were failed in correlation. All correlations give positive $\rho$ values. This shows that the normal substituent effect operates in all systems. The failure in correlation is attributed to the conjugative structure shown in Figure. 1.

In view of the inability of the Hammett $\sigma$ constants to produce individually satisfactory correlations with the imine proton chemical shifts, the authors think that, it is worthwhile to seek multiple correlations involving either $\sigma_{I}$ and $\sigma_{R}$ constants or Swain- Lupton's [20] F and R parameters. This is shown in the following equations 5 and 6 for protons:

$$
\begin{gathered}
\delta_{\mathrm{CH}}{ }^{(\mathrm{ppm})}=8.217( \pm 1.641)+0.568( \pm 0.044) \sigma_{\mathrm{I}}-0.070( \pm 0.003) \sigma_{\mathrm{R}} \\
(\mathrm{r}=0.951, \mathrm{n}=8, p>95 \%) \\
\delta_{\mathrm{CH}}{ }^{(\mathrm{ppm})}=8.281( \pm 0.177)+0.063( \pm 0.005) \mathrm{F}+0.156( \pm 0.027) \mathrm{R} \\
(r=0.957, \mathrm{n}=8, p>95 \%)
\end{gathered}
$$

\section{${ }^{13}$ C NMR spectra}

Physical organic chemists and researchers $[11,17,18,19]$ have made extensive study of ${ }^{13} \mathrm{C}$ NMR spectra for a large number of imines, ketones, styrenes, styryl ketones and keto-epoxides, acyl chlorides, bromides and their esters. They have studied the linear correlation of the chemical shifts (ppm) of $\mathrm{C}_{\alpha}, \mathrm{C}_{\beta}$ and $\mathrm{CO}$ carbons with Hammett $\sigma$ constants in alkenes, alkynes, acid chlorides and styrenes. In the present study, the chemical shifts (ppm) of imine $\mathrm{C}=\mathrm{N}$ carbon, have been assigned and are presented in Table 3. Attempts have been made to correlate the $\delta \mathrm{C}=\mathrm{N}$ chemical shifts $(\mathrm{ppm})$ with Hammett substituent constants, field and resonance 
parameters, with the help of single and multi-regression analyses to study the reactivity through the effect of substituents.

The chemical shifts (ppm) observed for the $\delta \mathrm{C}=\mathrm{N}$ have been correlated [12, 17-19] with Hammett constants and the results of statistical analysis are presented in Table 3 . The $\delta \mathrm{C}=\mathrm{N}$ chemical shifts (ppm) give satisfactory correlation with Hammett $\sigma$ constants. The remaining Hammett $\sigma^{+}, \sigma_{\mathrm{I}}, \sigma_{\mathrm{R}}, \mathrm{F}$ and $\mathrm{R}$ parameters are found to fail in correlation. This is due to the reason stated earlier with resonance conjugative structure as shown in Figure. 1.

In view of inability of some of the $\sigma$ constants to produce individually satisfactory correlation, the authors think that it is worthwhile to seek multiple correlation involving all $\sigma_{\mathrm{I}}$, $\sigma_{\mathrm{R}}, \mathrm{F}$ and $\mathrm{R}$ parameters [20]. This is given in the following correlation equations 7 and 8 .

$$
\begin{gathered}
\delta_{\mathrm{C}=\mathrm{N}}{ }^{(\mathrm{ppm})}=162.46( \pm 1.434)+2.908( \pm 0.392) \sigma_{\mathrm{I}}+1.417( \pm 0.325) \sigma_{\mathrm{R}} \\
(r=0.939, \mathrm{n}=8, \mathrm{p}>90 \%) \\
\delta_{\mathrm{C}=\mathrm{N}}{ }^{(\mathrm{ppm})}=162.43( \pm 1.549)+2.700( \pm 0.468) \mathrm{F}+1.043( \pm 0.239) \mathrm{R} \\
(r=0.933, \mathrm{n}=8, \mathrm{p}>90 \%)
\end{gathered}
$$

\section{CONCLUSIONS}

A series of $\mathrm{N}, \mathrm{N}^{\prime}$-arylidineethane-1,2-diamines have been synthesised by oxidative coupling reaction of ethylene diamine and aryl aldehydes. The purities of these diimines were checked by their analytical and spectroscopic data. The spectral frequencies of the functional groups of diimines have been assigned and correlated with Hammett substituent constants, F and R parameters. From the results of the statistical analysis, the effects of substituents on the functional group of diimines have been discussed.

\section{ACKNOWLEDGEMENTS}

The author thank The UGC-Chemistry Network Resource Centre, School of Chemistry, Central University, Hyderabad-500 040, for providing financial assistance through Summer Visiting Fellowship-June 2006, under the guidance of Prof. Dr. Mariappan Periasamy for initiating this diimines synthesizing work.

\section{REFERENCES}

1. Schiff, H. Annalen. 1864, 131, 118.

2. (a). Sersen, F.; Walko, M.; Loos, D. Chem. Commun. 2003, 2598;

(b) Reyes, A.; Najera, J.; Mendoza, R.; Grau, E.M.I.; Espinosa, E.; Salgado, H.; Tamariz, J.; Soriano, M.; Pannerselvam, K. Supramol. Chem. 1999, 11, 17;

(c) Curreli, S.; Adan, E.C.E.; Buchholz, J.B.; Kleji, A.W. J. Org. Chem. 2007, 72, 7018;

(d). McCarroll, A. RSC Adv. Chem. Sci. Synthetic page 2001, 163;

(d) Bigdeli, M.A.; Alavi Nikje, M.M.; Heravi, M.M. Phosporous, Sulfur, silicon Related Elements 2002, 177, 2309; (e). Lockea, J.M.; Griffithb, R.; Baileya, T.D.; Crumbiea, R.L. Tetrahedron 2009, 65, 10685.

3. (a). Das, S.; Das, V.K.; Saikia, L.; Thakur, A.J. Green Chem. Lett. Rev. 2012, 5, 457; (b) Espinosa Leija, A.; Bernès, S.; Hernández, G.; Sharma, P.; Peña, U.; Gutiérrez, R. Acta Cryst. 2009, E65, o2317; (c) Naemi, H.; Salami, F.; Rabiei, K. J. Mol. Cat. (Chemical). 2006, 260A, 100; (d). Benito, A.; Cano, J.; Mánez, R.M.; Soto, J.; Payá, J.; Lioret, F.; Julve, M.; Faus, J.; Dolores Marcos, M. Inorg. Chem. 1993, 32, 1197; (d). Muppidi, V.K.; Htwe, T.; Zcharias, P.S.; Pal, S. Inorg. Chem. Commun. 2004, 7, 1045. 
4. (a). Vairaprakash, P.; Periasamay, M. J. Org. Chem. 2006, 71, 3636; (b). Reyes-Arellano, R.; Bose, A.; Settler, I.; Sustamann, R. Structural Chem. 1995, 6, 391; (c). Vairaprakash, P.; Periasamay, M. Tetrahedron Lett. 2008, 48, 1233.

5. (a). Barluenga, J.; Olano, B.; Fustero, S. J. Org. Chem. 1983, 20, 2255; (b). Arduengo, A. J.; Krafczyk, R.; Schmutzler, R. Tetrahedron. 1999, 35, 14523.

6. (a). Armesto, D.; Bosch, P.; Gallego, M.G.; Martin, J.F.; Ortiz, M.J.; Perez-Ossorio, R. Org. Prep. Proced. Int. 1987, 19, 181; (b). Pagadala, R.; Meshram, J.S.; Chopde, H.N.; Jetti, V. Int. J. Chem Tech Res. 2010, 2, 1581; (c) Ali, P.; Meshram, J.; Tiwari, V.; Dongre, R.; Sheikh, J.; Ahamed, M. Der. Parm. Chem. 2010, 2, 138.

7. (a) Guo, C.; Jin, G.X.; Wang, F. J. Polym Sci. Polym Chem. 2004, 42A, 4830; (b). Munro, O.Q.; Camp, G.L. Acta Cryst. 2003, 59C, o672; (c). Appukuttan, V.K.; Liu, Y.; Son, B.C.; Ha, C.S.; Suh, H.; Kim, I.L. Organomettallics 2011, 30, 2285.

8. (a). Arney, A.; Meth-Cohn, O.; Nyerges, M. Org. Biomol. Chem. 2003, 1, 1545; (b). Fukuzawa, S.; Kpmuro, Y.; Nakano, N.; Obara, S. Tetrahedron Lett. 2003, 44, 3671; (c). Barf, T.; Jansen, J. F.G.A.; Bolhuis, F.; Spek, A.L.; Feringa, B.L.; Recl. Trav. Chim. PaysBas. 1993, 112, 376; (d). Takehiko, H.; Shinichi, E.; Shinichi, F.; Rare Earths. 2003, 42, 66; (e). Amoroso, A.J.; Coogan, M.P.; Dunne, J.E.; Moreira, V.F.; Hess, J.B.; Heys, A.J.; Lloyd, D.; Millet, C.; Pope, S.M.A.; Williams, C. Chem. Commun. 2007, 3066; (f). Congiglio, G.; Failla, S.; Finocchiaro, P.; Oliveri, I. P.; Bella, S.D. Dalton Trans. 2012, 41, 387; (g). Jin, X. D.; Jin, Y.H.; Cui, Z.G.; Li, Y.Y.; Wang, H.B. Adv. Mat. Res. 2011, $197,627$.

9. Serson, F.; Walko, M.; Loos, D. Gen. Physiol. Biophys. 2009, 28, 210.

10. Sharma, V.; Khan, M.S.Y. Eur. J. med. Chem. 2001, 36, 651.

11. Thirunarayanan, G.; Gopalakrishnan, M.; Vanangamudi, G. Spectrochim. Acta 2007, $67 \mathrm{~A}, 1106$.

12. Suresh, R.; Kamalakkannan, D.; Ranganathan, K.; Arulkumaran, R.; Sundararajan, R.; Sakthinathan, S.P.; Vijayakumar, S.; Sathiyamoorthy, K.; Mala, V.; Vanangamudi, G.; Thirumurthy, K.; Mayavel, P.; Thirunarayanan, G. Spectrochim. Acta 2013, 101A, 239.

13. Worman, J.J.; Schimidt, E.A.; Olson, E. S.; Jensen, W.P.; Schultz, R.D. Spectrochim. Acta 1976, 32A, 1419

14. Flett, M.St.C. Trans. Faraday Soc. 1948, 44, 767.

15. Thirunarayanan, G.; Vanangamudi, G.; Sathiyendiran, V.; Ravi, K. Indian J. Chem. 2011, $50 \mathrm{~B}, 593$.

16. Ouali, A.; Spindler, J.F.; Ctristau, H.J.; Taillefer, M. Chem. A Eur. J. 2005, 11, 2483.

17. Thirunarayanan, G.; Vanangamudi, G. Spectrochim. Acta 2011, 81A, 390.

18. Ranganathan, K.; Suresh, R.; Kamalakkannan, D.; Arulkumaran, R.; Sundararajan, R.; Sakthinathan, S.P.; Vijayakumar, S.; Vanangamudi, G.; Thirumurthy, K.; Mayavel, P.; Thirunarayanan, G. Int. Lett. Chem. Phy. Astro. 2012, 4, 66.

19. Sakthinathan, S.P.; Vanangamudi, G.; Thirunarayanan, G. Spectrochim. Acta 2012, 95A, 693.

20. Swain, C.G.; Lupton, E.C.Jr. J. Am. Chem. Soc. 1968, 90, 4328. 